\title{
Margaret McCartney: General practice is going the way of NHS dentistry
}

\author{
Margaret McCartney GP
}

Glasgow

General practice is quietly going the way of UK dentistry. This will widen health inequalities, decrease doctors' job satisfaction, and do nothing to fix problems in general practice.

In 2006 the NHS dental contract was changed to fulfil "activity targets," with banded rates, for "units of dental activity." This has been deeply unpopular. Dentists who exceed the limit are not paid extra, and very different treatments-such as extraction and root canal filling - attract the same pay. Newspapers have reported patients being offered expensive private work for treatments available on the NHS. ${ }^{1}$ High street dentists offer cosmetic treatments, while some patients can't find an NHS dentist at all. ${ }^{2-4}$

Several companies offer similar private sidelines to general practice. GPs are busy, overstretched, and lacking in job satisfaction—so why wouldn't a stressed GP want to work for more money, with longer appointments, on a private basis?

Doctaly, which doesn't see patients with psychiatric problems or chronic diseases, offers an app based appointment system in London and plans to expand.

The independent contractor model, which probably saved the NHS money in the first 70 years, will strangle it from within

The GP contract means that, although you can't see your own patients privately, you can see another doctor's through Doctaly. This disrupts continuity, and costs may well rise. It's tempting to think that it could reduce waiting times; but, if more GPs do more private practice, fewer will be available for people who need urgent care but can't afford private prices.

Several private companies offer GP consultations over Skype, offering to treat ear infections or constipation without examining the patient. One company will write sick notes and referrals, ${ }^{6}$ but it told me that "a direct referral can only be made to private services."

Private GP visiting services advertise 25 minute appointments at home. ${ }^{7}$ This is internet enabled NHS fragmentation and destruction in action.
Firstly, we urgently need the government to act to protect the NHS from inappropriate workloads passed to it from the private sector. Secondly, NHS guidance allowing patients to mix private and NHS care is outdated in an age of apps that blur the lines between NHS and private medicine-and is this kind of concierge clinic actually safe $?^{8}$ Thirdly, the NHS's founding principles don't allow money, rather than clinical need, to determine whether you can see a GP quickly.

There is a way around this: GPs who can offer more hours to the NHS should be able to do so.

The independent contractor model, which probably saved the NHS money in the first 70 years of the NHS, will now strangle it from within. A moral argument can be made for keeping NHS GPs in the service as employees, similar to consultants. I hope that the government will make this argument. I know that it will not.

Competing interests: See www.bmj.com/about-bmj/freelancecontributors/margaret-mccartney.

Provenance and peer review: Commissioned; not externally peer reviewed.

1 Hoyle A. Could your dentist be destroying your teeth? Daily Telegraph 2015 Jan 9. www. telegraph.co.uk/news/health/11350853/Could-you-dentist-be-destroying-your-teeth.html. Kilcoyne T, Jacobs AV, Mayhew M, et al. Letter: The NHS dental health system is unfit for purpose. Daily Telegraph 2016 Jan 4. www.telegraph.co.uk/comment/letters/12077501/ Letter-The-NHS-dental-health-system-is-unfit-for-purpose.html.

3 Davies P. NHS dentists in Shipley-update. 5 May 2016. https://www.philip-davies.org. uk/news/nhs-dentists-shipley-update.

4 NHS England. GP patient survey dental statistics; January to March 2016, England. $7 \mathrm{Jul}$ 2016. https://www.england.nhs.uk/statistics/2016/07/07/gpps dent y10w23357969/.https: //www.england.nhs.uk/statistics/2016/07/07/gpps_dent_y10w23357969/

5 Doctaly. Latest topics. https://www.doctaly.com/faq/.

6 Push Doctor. Constipation symptoms, causes and treatment. https://www.pushdoctor.co. uk/what-we-treat/digestive-problems/constipation-symptoms.

GPDQ. www.gpdq.co.uk.

8 Department of Health. Guidance on NHS patients who wish to pay for additional private care. 23 Mar 2009. https://www.gov.uk/government/uploads/system/uploads/attachment data/file/404423/patients-add-priv-care.pdf.

Published by the BMJ Publishing Group Limited. For permission to use (where not already granted under a licence) please go to http://group.bmj.com/group/rights-licensing/ permissions 
